\title{
Changes in mRNA Expression and Activity of Xenobiotic Metabolizing Enzymes in Livers from Adjuvant-Induced Arthritis Rats
}

\author{
Atsushi Kawase, Syoko Wada, Masahiro Iwaki* \\ Department of Pharmacy, School of Pharmacy, Kinki University, Osaka, Japan. \\ Email: ${ }^{*}$ iwaki@phar.kindai.ac.jp \\ Received June $26^{\text {th }}, 2013$; revised August $1^{\text {st }}, 2013$; accepted August $16^{\text {th }}, 2013$ \\ Copyright (C) 2013 Atsushi Kawase et al. This is an open access article distributed under the Creative Commons Attribution License, \\ which permits unrestricted use, distribution, and reproduction in any medium, provided the original work is properly cited.
}

\begin{abstract}
Pathophysiological changes in human patients and in animal models of infection or inflammation are associated with alterations in the production of numerous liver-derived proteins including metabolizing enzymes. In this study, the effects of adjuvant-induced arthritis (AA) in rats on the levels of mRNA and activity of hepatic xenobiotic metabolizing enzymes were determined during the inflammatory response. The mRNA levels of cytochrome P450 (CYP) 1A2, CYP2C12, CYP2D1, CYP2D2, and CYP3A1 were significantly decreased compared with control levels in almost all phases of inflammation. A reduction in the activity of CYP2C and CYP3A, which are abundantly expressed in the liver, was also observed. For phase II metabolizing enzymes, mRNA levels of uridine 5'-diphospho-glucuronosyltransferase (UGT) 1A1, UGT1A6, sulfotransferase (SULT) 2A1, and glutathione S-transferase 2 were significantly decreased compared with control levels. However, the mRNA levels of UGT2B and SULT1A1 returned to control levels during the subacute ( $7 \mathrm{~d}$ after adjuvant treatment) and chronic ( $21 \mathrm{~d}$ after adjuvant treatment) phases although these levels decreased during the acute ( $3 \mathrm{~d}$ after adjuvant treatment) phase. These results suggest that the effects of inflammation on the expression of xenobiotic metabolizing enzymes differ depending on the isoform of the enzyme and could affect the pharmacokinetics of each substrate.
\end{abstract}

Keywords: Inflammation; Arthritis; Enzyme; Cytochrome; Metabolism

\section{Introduction}

Pathophysiological changes in human patients and in animal models of infection or inflammation are associated with immediate and often dramatic alterations in the production of numerous liver-derived proteins, including metabolizing enzymes such as cytochrome P450s (CYP), UDP-glucuronosyltransferases (UGT), sulfotransferases (SULT), and glutathione S-transferases (GST) [1,2]. Inflammatory conditions such as rheumatoid arthritis and Crohn's disease have been shown to reduce hepatic clearance of several highly cleared drugs [3-5]. Adjuvant-induced arthritis (AA) in rats has been used as an animal model for rheumatoid arthritis in the development of new anti-inflammatory medicines because rats exhibit a systemic inflammatory disease with similar bone and cartilage alterations to those observed in rheumatoid arthritis on day 3 (acute), day 7 (subacute) and day 21

"Corresponding author. (chronic) after adjuvant treatment [6]. Changes in the pharmacokinetics and pharmacological effects of several drugs via altered CYP activities and serum protein binding have been reported in AA rats, including elevated plasma concentrations of cyclosporine A, acebutolol and propranolol $[4,7]$, and prolongation of sleeping time with pentobarbital [8]. We also demonstrated that flurbiprofen glucuronidation activity and CYP content in liver microsomes were reduced [9] and intestinal CYP3A activity was decreased in AA rats [10]. Inflammatory cytokines, for example, tumor necrosis factor (TNF)- $\alpha$, interleukin (IL)- 6 , and IL-1 could be involved in the decrease of metabolizing enzymes [11-13]. The nuclear receptor NR1I2, which is a pregnane $\mathrm{X}$ receptor (PXR) and NR1I3, which is a constitutive androstane receptor (CAR), is involved in the regulation of CYP transcription by interacting with xenobiotics and endogenous toxins [14-16].

However, a comprehensive understanding of the changing profile of xenobiotic metabolizing enzymes in acute 
( $3 \mathrm{~d}$ after adjuvant treatment), subacute ( $7 \mathrm{~d}$ after adjuvant treatment) and chronic ( $21 \mathrm{~d}$ after adjuvant treatment) phases of inflammation remains elusive, despite their importance on the pharmacokinetics of drug-related substrates. In this study, we examined the influence that the inflammatory response in an AA rat model has on hepatic enzymes involved in phase I (CYP1A2, CYP2C11, CYP2D1, CYP2D2, and CYP3A1) and phase II (SULT1A1, SULT2A1, UGT1A1, UGT1A6, UGT2B, and GSTP2) metabolism.

\section{Materials and Methods}

\subsection{Preparation of AA Rats}

Female Sprague-Dawley rats (seven weeks old), weighing 180 - $240 \mathrm{~g}$, were purchased from CLEA Japan, Inc. (Tokyo, Japan). The animals were housed in a temperature-controlled room with free access to standard laboratory chow and water. Adjuvant was prepared from 100 mg heat-killed Mycobacterium butyricum (Difco Laboratories, Detroit, MI, USA) suspended in $10 \mathrm{~mL}$ of Bayol $\mathrm{F}$ oil. Hindpaw volumes were measured by liquid plethysmometry. Animals were studied 5, 10, 24 and $3 \mathrm{~d}$ (acute phase), $7 \mathrm{~d}$ (subacute phase), and 14 and $21 \mathrm{~d}$ (chronic phase) after the injection of adjuvant or Bayol F. AA rats in the acute phase exhibit local inflammation at the treated site. In the chronic phase, severe inflammation was observed in local and systemic sites. The experiments were approved by the Committee for the Care and Use of Laboratory Animals at Kinki University School of Pharmacy.

\subsection{Measurement of mRNA}

After the animals were anesthetized with diethyl ether, the liver was perfused with ice-cold saline and then removed. After flash freezing in liquid nitrogen, each sample was preserved at $-80^{\circ} \mathrm{C}$ until used for RNA extraction.

Determination of mRNA levels was performed using real-time reverse transcriptase polymerase chain reaction (RT-PCR) as previously described [17]. Total RNA (500 ng) was extracted from each liver and reverse-transcribed to complementary DNA (cDNA) using a PrimeScript-RT reagent Kit (TaKaRa, Shiga, Japan). Reactions were incubated for $15 \mathrm{~min}$ at $37^{\circ} \mathrm{C}$ and $5 \mathrm{sec}$ at $85^{\circ} \mathrm{C}$. The reverse-transcribed cDNA was used as a template for realtime RT-PCR. Amplification was performed in $50 \mu \mathrm{L}$ reaction mixtures containing $2 \times$ SYBR Premix Ex Taq (TaKaRa) and $0.2 \mathrm{mM}$ of each primer set shown in Table 1. PCRs were incubated at $95^{\circ} \mathrm{C}$ for $10 \mathrm{sec}$, and then amplified at $95^{\circ} \mathrm{C}$ for $5 \mathrm{sec}, 55^{\circ} \mathrm{C}$ for $20 \mathrm{sec}$, and $72^{\circ} \mathrm{C}$ for $31 \mathrm{sec}$ for 40 cycles. Data was normalized to the amount of $18 \mathrm{~S}$ rRNA in each sample. The data were analyzed
Table 1. Primer sequences used in PCR assays.

\begin{tabular}{|c|c|c|}
\hline Gene & & Primer sequence $\left(5^{\prime}-3^{\prime}\right)$ \\
\hline \multirow{2}{*}{ CYP1A2 } & Forward: & ACGTGAGCAAAGAGGCTAACCA \\
\hline & Reverse: & ATTAGCCACCGATTCCACCAC \\
\hline \multirow{2}{*}{ CYP2C11 } & Forward: & CGCACGGAGCTGTTTTTGTT \\
\hline & Reverse: & GCAAATGGCCAAATCCACTG \\
\hline \multirow{2}{*}{ CYP2D1 } & Forward: & GCAAAGTCTTCCCCAAGCTCA \\
\hline & Reverse: & GGAAGGCATCAGTCATGTCTCG \\
\hline \multirow{2}{*}{ CYP3A1 } & Forward: & GCCTTTTTTTGGCACTGTGCT \\
\hline & Reverse: & GCATTTGACCATCAAACAACCC \\
\hline \multirow{2}{*}{ SULT1A1 } & Forward: & GCCCGAAATGCAAAGGATG \\
\hline & Reverse: & TGCAGCTTGGCCATGTTGT \\
\hline \multirow{2}{*}{ SULT2A1 } & Forward: & CAGTAGCCCAAGCTGAAGCCTT \\
\hline & Reverse: & CGGCCATTTTCTCCTGGAAA \\
\hline \multirow{2}{*}{ UGT1A1 } & Forward: & CGGAGTTATTCAGCAGCTCCAG \\
\hline & Reverse: & GGTGCTATGACCACCACTTCGT \\
\hline \multirow{2}{*}{ UGT1A6 } & Forward: & AACCTAGAAGAGTTGCGGACCC \\
\hline & Reverse: & CAGCAAAGTGGTTGTTCCCAA \\
\hline \multirow{2}{*}{ UGT2B } & Forward: & TCCCCACCCAACATTACCAA \\
\hline & Reverse: & AGCAGGTTTGCAATGGAGTCC \\
\hline \multirow{2}{*}{ GSTP2 } & Forward: & GCAGCTCCCCAAGTTTGAAGA \\
\hline & Reverse: & GGTGCCTCAAGATGGCATTAGA \\
\hline \multirow{2}{*}{ 18S rRNA } & Forward: & CGCCGCTAGAGGTGAAATTC \\
\hline & Reverse: & CCAGTCGGCATCGTTTATGG \\
\hline
\end{tabular}

with ABI Prism 7000 SDS Software (Applied Biosystems) using the multiplex comparative method.

\subsection{Preparation of Hepatic Microsomes}

Livers were perfused with ice-cold saline and chopped into small pieces. A $25 \%(\mathrm{w} / \mathrm{v})$ homogenate was made in ice-cold $1.15 \% \mathrm{KCl}$ solution using a Physcotron homogenizer. The homogenate was centrifuged at $12,000 \mathrm{~g}$ for $20 \mathrm{~min}$, and the supernatant was further centrifuged at $105,000 \mathrm{~g}$ for $60 \mathrm{~min}$ to obtain a microsomal pellet. The microsomal pellet was washed by resuspending it in 3 $\mathrm{mL}$ of $1.15 \% \mathrm{KCl}$, and the suspension was centrifuged at $105,000 \mathrm{~g}$ for $30 \mathrm{~min}$ to obtain the final microsomal pellet, which was resuspended in $1.5 \mathrm{~mL}$ of $1.15 \% \mathrm{KCl}$ and stored at $-80^{\circ} \mathrm{C}$ until use. All procedures were carried out at $4^{\circ} \mathrm{C}$. Protein concentrations were determined using a BCA protein assay kit (Pierce Biotechnology, Rockford, IL, USA).

\subsection{CYP Activity Measurements}

CYP3A activity was determined using a P450-Glo CYP3A4 assay (Promega, Madison, WI, USA). P450Glo CYP3A4 was used to determine CYP3A1 and 
CYP3A2 activities in rats and CYP3A4 activity in humans as per the manufacturer's instructions. In brief, CYP3A reactions were performed in a 96-well plate (OptiPlate-96 (PerkinElmer, Waltham, MA, USA)). An incubation mixture $(50 \mu \mathrm{L}$ total volume) was prepared, containing $200 \mathrm{mM}$ potassium phosphate buffer ( $\mathrm{pH} 7.4$ ), NADPH regeneration system (Promega), $20 \mu$ g rat liver microsomes and $50 \mu \mathrm{M}$ of luciferin 6' benzyl ether (luciferin-BE) as a substrate for CYP3A1 and CYP3A2. The concentrations of luciferin-BE were around the $\mathrm{K}_{\mathrm{m}}$ values $(50 \mu \mathrm{M})$. After preincubation for $10 \mathrm{~min}$ at $37^{\circ} \mathrm{C}$, the reaction was initiated by addition of the NADPH regeneration system and then incubated for $30 \mathrm{~min}$ at $37^{\circ} \mathrm{C}$ with constant shaking. The reconstituted luciferin detection reagent $(50 \mu \mathrm{L})$ was then added to stop the reaction and to generate chemiluminescence. CYP3A converts luciferin-BE to luciferin by a debenzylation reaction and the production of luciferin by CYP3A1 and CYP3A2 was determined using a luciferase assay. Luminescence was measured using the FLUOstar Optima (Moritex, Tokyo, Japan). CYP2C9 activity was determined using a P450-Glo CYP2C9 assay (Promega). $100 \mu \mathrm{M}$ of 6'-deoxyluciferin (luciferin-H) was used as a substrate for CYP2C9. All other conditions were the same as for the CYP3A assay. CYP2C9 converts 6'-deoxyluciferin (luciferin-H) to luciferin and the production of luciferin by CYP2C9 was determined using a luciferase assay. All CYP isoform activity determinations were performed in duplicate.

\subsection{Statistical Analysis}

Separate control groups were made for acute, subacute and chronic phases. The differences between the AA and control groups for (each of) the three phases were estimated using the Student's unpaired $t$-test.

\section{Results and Discussion}

Changes in mRNA levels of various xenobiotic metabolizing enzymes from the CYP, UGT and SULT families and GSTP during each response phase of inflammation were determined. CYP1A2, CYP2C12, CYP2D1, CYP2D2, and CYP3A1 mRNA levels are shown in Figure 1. The mRNA level of all examined CYPs exhibited significant decreases $24 \mathrm{~h}$ after adjuvant treatment. Sanada et al. demonstrated that the hepatic mRNA and protein levels of inflammatory cytokines such as TNF- $\alpha$, IL-6, and IL-1 significantly increased by $24 \mathrm{~h}$ after adjuvant treatment in rats [18]. The increased cytokines in the early stage of inflammation could cause a reduction in CYP mRNA levels. It is reported that IL- $1 \beta$ inhibits the expression of various hepatic CYP isoforms [19]. The recovery of CYP1A2, CYP2C12, and CYP2D1 mRNA occurred by day 3 . All examined CYP mRNAs were re- duced to approximately half of control levels by day 21 (chronic phase).

These results showed that almost all examined CYP isoforms significantly decreased in the acute, and subacute and the chronic phases in the arthritic (rats) compared with control rats. In particular, CYP3A1 mRNA decreased to low levels $24 \mathrm{~h}$ after adjuvant treatment. It is possible that the diminished expression of CYP3A1 could affect the pharmacokinetics of substrates because CYP3A participates mainly in the metabolism of various drugs. Figure 2 shows the alterations in the activities of CYP2C and CYP3A, which have relatively high protein content in the liver in each phase of inflammation. The activity of $\mathrm{CYP} 2 \mathrm{C}$ decreased going from the acute to the chronic phase of inflammation and was less than $10 \%$ of control levels in the subacute and chronic phases of inflammation. The activity of CYP3A also significantly decreased at 3,14 and $21 \mathrm{~d}$, suggesting that both protein and mRNA levels had decreased. Total CYP2C metabolizing activity showed a further decrease compared with the mRNA level of CYP2C12 in AA rats. It could be that the changes in expression of these other CYP2C isoforms, such as CYP2C6 and CYP2C7, accounted for this difference between activity and mRNA level.

These results could be interpreted to mean that the expression of all examined CYP isoforms were suppressed during inflammation and this decreased activity could affect the pharmacokinetics of various drugs. The transcription of CYPs is regulated by nuclear receptors such as PXR and CAR. For example, the transcription of CYP2B and CYP3A is known to be regulated through CAR and PXR, respectively [20,21]. CAR and PXR show overlapping regulation of transcription of CYPs and transporters [22]. The effects of the phases of inflammation on the expression of nuclear receptors are unclear but warrant examination.

To further clarify the effects of AA on other metabolizing enzymes, we examined the alterations of SULTs, UGTs and GSTP involved in the phase II metabolic pathway. The changes in mRNA of three isoforms of UGTs (UGT1A1, UGT1A6, and UGT2B) are shown in Figure 3. UGT1A1 and UGT1A6 mRNAs exhibited significant decreases in the acute, subacute, and chronic phases of inflammation. On the other hand, UGT2B showed little change from control levels except on day one (acute phase). Interestingly, the distinct effects of AA on the mRNA levels of UGT unlike CYP isoforms were presented. The UGT1 locus is located on chromosome $2 \mathrm{q} 37$ and the UGT2 family is located on chromosome 4q13. UGT1A participates in the metabolism of endobiotic substrates such as bilirubin and estrogens and drug substrates such as irinotecan, imipramine and cyproheptadine [23]. It is possible that the metabolism of substrates by UGT1A was affected by the inflammatory 

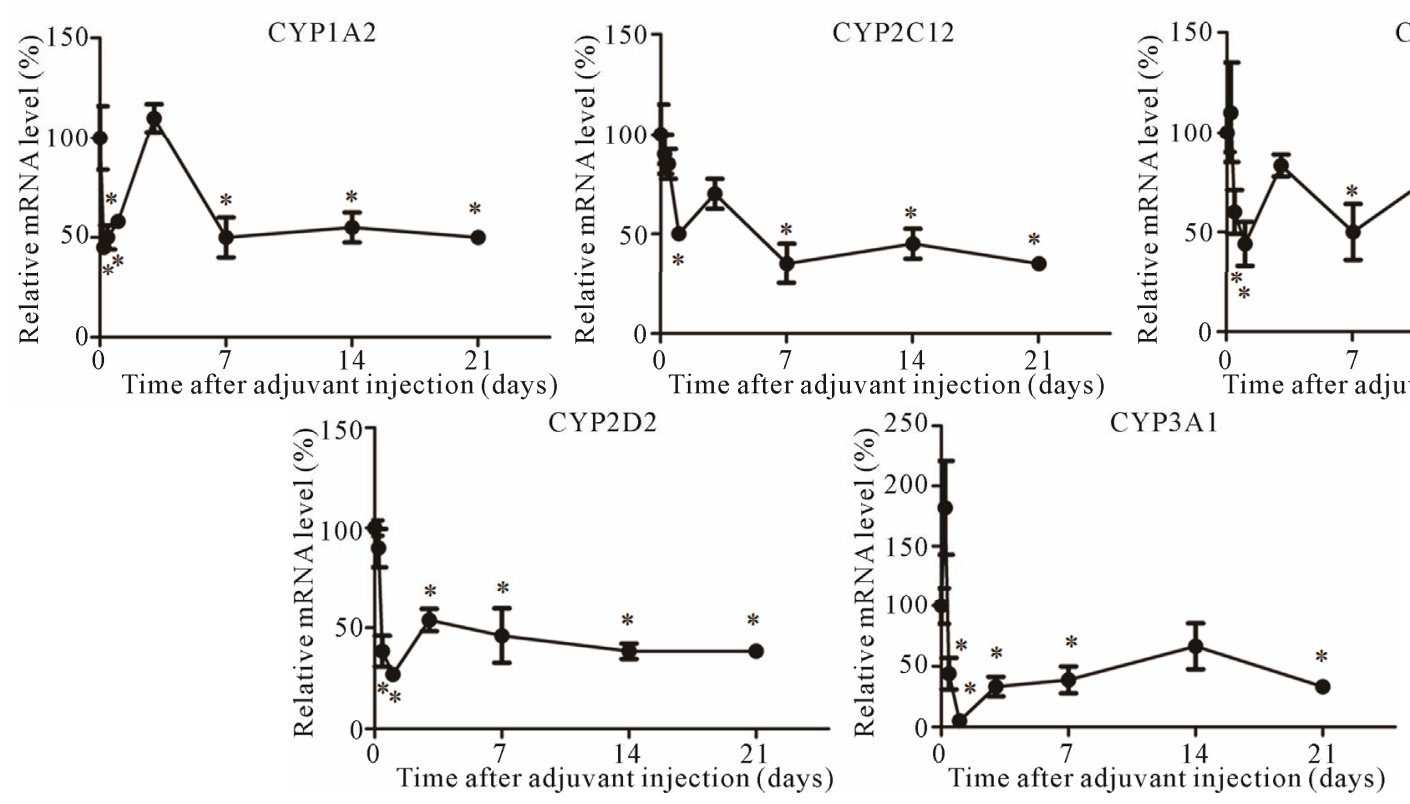

Figure 1. Changes in relative mRNA levels of CYP1A2, 2C12, 2D1, 2D2, and 3A1 in the liver of AA rats. The results are expressed as the mean \pm S.D. $(n=4)$. There were significant differences between control and AA rats $\left({ }^{*} p<0.05\right)$.
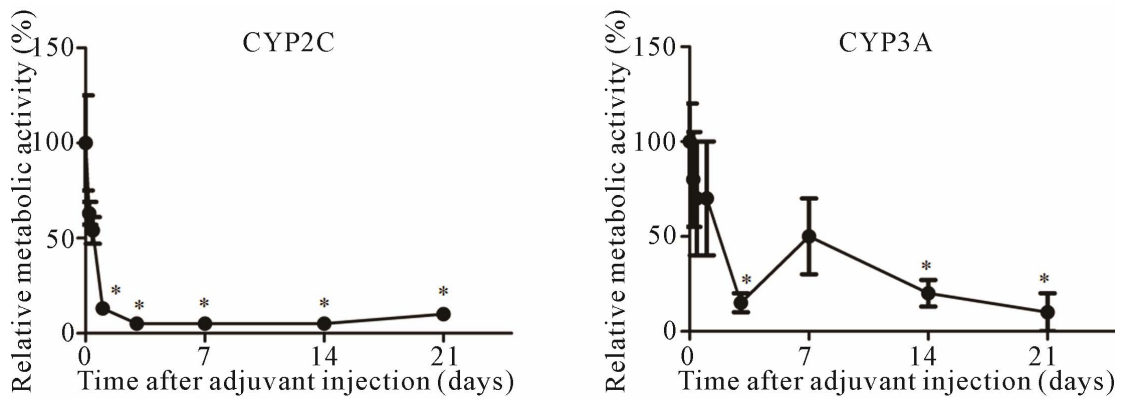

Figure 2. Changes in relative metabolic activities of CYP2C and $3 A$ in the liver of AA rats. The results are expressed as the mean \pm S.D. $(n=4)$. There were significant differences between control and AA rats $\left({ }^{*} p<0.05\right)$.
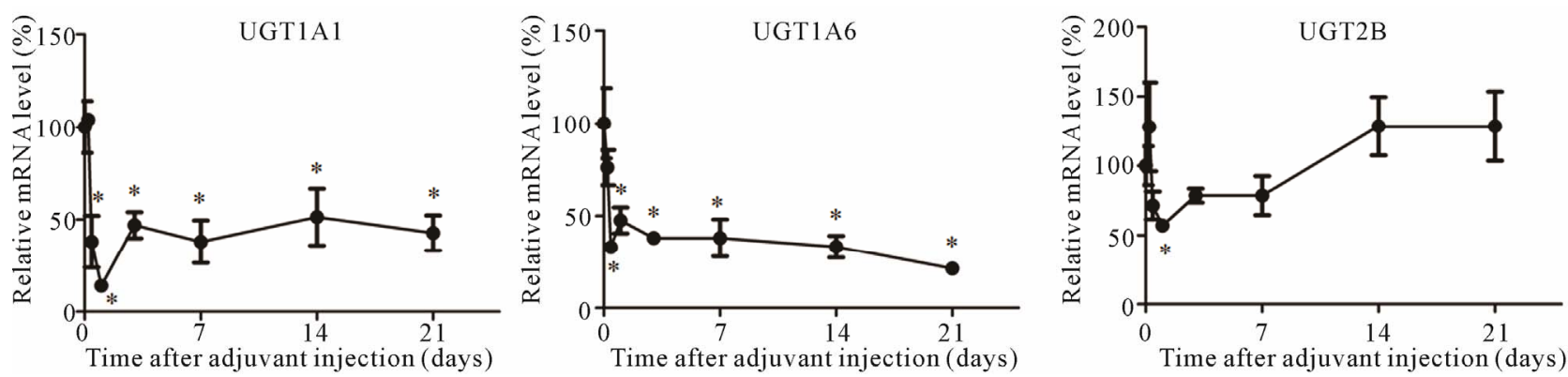

Figure 3. Changes in relative mRNA levels of UGT1A1, 1A6, and $2 B$ in the liver of AA rats. The results are expressed as the mean \pm S.D. $(n=4)$. There were significant differences between control and AA rats $\left({ }^{*} p<0.05\right)$.

response in AA rats. It has been reported that UGT1A and UGT2B are regulated by the aryl hydrocarbon receptor and NF-E2-related factor 2, respectively [24,25]. These different mechanisms in transcriptional regulation could lead to differences in the expression of UGT isoforms. Our future research will be focused on investigat- ing alterations between UGTs and transcription factors.

The changes in mRNA of SULT1A1, SULT2A1 and GSTP2 are shown in Figure 4. The SULTs are categorized into two major groups, the arylsulfotransferases (SULT1 family) and the hydroxysteroid sulfotransferases (SULT2 family) [26]. Although both SULT1A1 and 

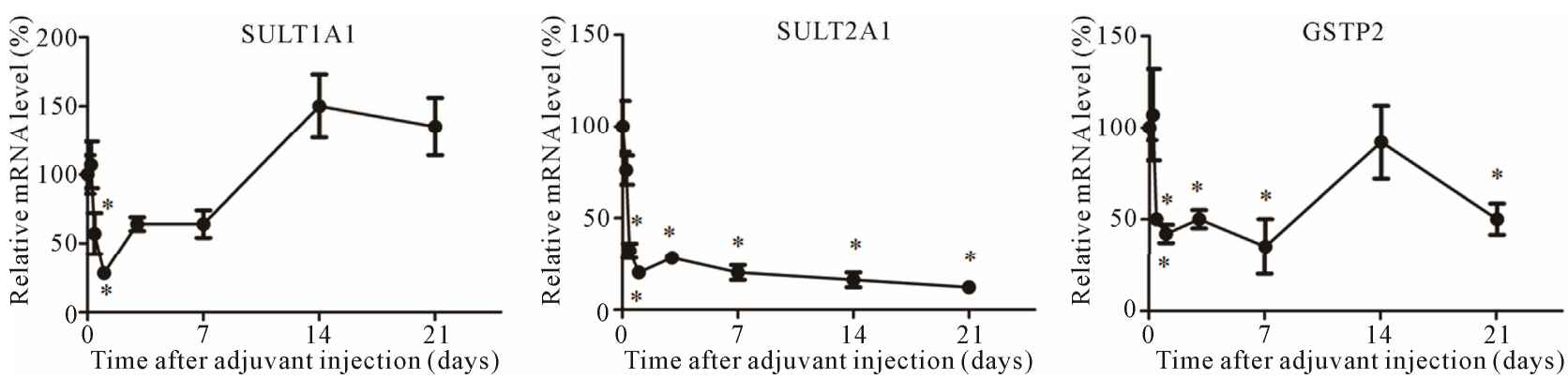

Figure 4. Changes in relative mRNA levels of SULT1A1, 2A1, and GSTP2 in the liver of AA rats. The results are expressed as the mean \pm S.D. $(n=4)$. There were significant differences between control and AA rats $\left({ }^{*} p<0.05\right)$.

SULT2A1 mRNAs decreased in the acute phase, the mRNA level of SULT1A1 but not SULT2A1 recovered to control levels in the subacute and chronic phases. It has been reported that SULT2A1 is predominantly regulated by PXR $[27,28]$. In our previous report, we demonstrated that the mRNA level of PXR but not CAR was significantly decreased in AA rats [29]. Therefore, it is possible that the inflammatory response could lead to the inhibition of transcription of SULT2A1 through regulation of PXR levels. Further research is needed to better understand the differences in regulation between SULT1A1 and SULT2A1. The mRNA level of GSTP2 decreased by close to $50 \%$ in all phases. These results suggest that phase II enzymes could have more distinct patterns of changes in mRNA for each isoform compared with CYPs.

In conclusion, the mRNA level of almost all metabolizing enzymes examined were decreased in all three response phases in AA rats, suggesting that the inflamematory condition could affect the pharmacokinetics of substrates used by these enzymes, most likely as a result of decreased protein expression. However, some enzymes such as UGT2B and SULT1A1 showed a relatively quick recovery to control mRNA levels, indicating that the effects of inflammation on mRNA levels of metabolizing enzymes differ depending on the isoform.

\section{Acknowledgements}

This work was supported in part by the "High-Tech Research Center" Project for Private Universities: matching fund subsidy from MEXT (Ministry of Education, Culture, Sports, Science and Technology), 2007-2011.

\section{REFERENCES}

[1] A. E. Aitken, T. A. Richardson and E. T. Morgan, "Regulation of Drug-Metabolizing Enzymes and Transporters in Inflammation," Pharmacology and Toxicology, Vol. 46, 2006, pp. 123-149. doi:10.1146/annurev.pharmtox.46.120604.141059

[2] K. W. Renton, "Cytochrome P450 Regulation and Drug
Biotransformation during Inflammation and Infection," Current Drug Metabolism, Vol. 5, No. 3, 2004, pp. 235243. doi: $10.2174 / 1389200043335559$

[3] F. M. Belpaire, F. D. Smet, B. F. Chidavijak, N. Fraeyman and M. G. Bogaert, "Effect of Turpentine-Induced Inflammation on the Disposition Kinetics of Propranolol, Metoprolol, and Antipyrine in the Rat," Fundamental \& Clinical Pharmacology, Vol. 3, No. 2, 1989, pp. 79-88. doi:10.1111/j.1472-8206.1989.tb00667.x

[4] M. Piquette-Miller and F. Jamali, "Selective Effect of Adjuvant Arthritis on the Disposition of Propranolol Enantiomers in Rats Detected Using a Stereospecific HPLC Assay," Pharmaceutical Research, Vol. 10, No. 2, 1993, pp. 294-299. doi:10.1023/A:1018907431893

[5] M. E. Laethem, F. M. Belpaire, P. Wijnant, M. T. Rosseel and M. G. Bogaert, "Influence of Endotoxin on the Stereoselective Pharmacokinetics of Oxprenolol, Propranolol, and Verapamil in the Rat," Chirality, Vol. 6, No. 5, 1994, pp. 405-410. doi:10.1002/chir.530060508

[6] R. O. Williams, M. Feldmann and R. N. Maini, "AntiTumor Necrosis Factor Ameliorates Joint Disease in Murine Collagen-Induced Arthritis," Proceedings of the $\mathrm{Na}$ tional Academy of Sciences of the United States of America, Vol. 89, No. 20, 1992, pp. 9784-9788. doi:10.1073/pnas.89.20.9784

[7] N. Shibata, H. Shimakawa, T. Minouchi and A. Yamaji, "Pharmacokinetics of Cyclosporin A after Intravenous Administration to Rats in Various Disease States," Biological \& Pharmaceutical Bulletin, Vol. 16, No. 11, 1993, pp. 1130-1135. doi:10.1248/bpb.16.1130

[8] G. Dipasquale, P. Welaj and C. L. Rassaert, "Prolonged Pentobarbital Sleeping Time in Adjuvant-Induced Polyarthritic Rats," Research Communications in Chemical Pathology and Pharmacology, Vol. 9, No. 2, 1974, pp. 253-264.

[9] T. Nagao, T. Tanino and M. Iwaki, "Stereoselective Pharmacokinetics of Flurbiprofen and Formation of Covalent Adducts with Plasma Protein in Adjuvant-Induced Arthritic Rats," Chirality, Vol. 15, No. 5, 2003, pp. 423428. doi:10.1002/chir.10227

[10] S. Uno, A. Kawase, A. Tsuji, T. Tanino and M. Iwaki, "Decreased Intestinal CYP3A and P-Glycoprotein Activities in Rats with Adjuvant Arthritis," Drug Metabolism and Pharmacokinetics, Vol. 22, No. 4, 2007, pp. 313-321. 


\section{doi:10.2133/dmpk.22.313}

[11] G. W. Warren, S. M. Poloyac, D. S. Gary, M. P. Mattson and R. A. Blouin, "Hepatic Cytochrome P-450 Expression in Tumor Necrosis Factor-Alpha Receptor (p55/p75) Knockout Mice after Endotoxin Administration," Journal of Pharmacology and Experimental Therapeutics, Vol. 288, No. 3, 1999, pp. 945-950.

[12] E. Siewert, R. Bort, R. Kluge, P. C. Heinrich, J. Castell and R. Jover, "Hepatic Cytochrome P450 Down-Regulation during Aseptic Inflammation in the Mouse Is Interleukin 6 Dependent," Hepatology, Vol. 32, No. 1, 2000, pp. 49-55. doi:10.1053/jhep.2000.8532

[13] E. T. Morgan, "Regulation of Cytochrome P450 by Inflammatory Mediators: Why and How?" Drug Metabolism and Disposition, Vol. 29, No. 3, 2001, pp. 207-212.

[14] P. Honkakoski, I. Zelko, T. Sueyoshi and M. Negishi, "The Nuclear Orphan Receptor CAR-Retinoid X Receptor Heterodimer Activates the Phenobarbital-Responsive Enhancer Module of the CYP2B Gene," Molecular and Cellular Biology, Vol. 18, No. 10, 1998, pp. 5652-5658.

[15] S. A. Kliewer, J. T. Moore, L. Wade, J. L. Staudinger, M. A. Watson, S. A. Jones, D. D. McKee, B. B. Oliver, T. M. Willson, R. H. Zetterstrom, T. Perlmann and J. M. Lehmann, "An Orphan Nuclear Receptor Activated by Pregnanes Defines a Novel Steroid Signaling Pathway," Cell, Vol. 92, No. 1, 1998, pp. 73-82. doi:10.1016/S0092-8674(00)80900-9

[16] D. J. Waxman, "P450 Gene Induction by Structurally Diverse Xenochemicals: Central Role of Nuclear Receptors CAR, PXR, and PPAR," Archives of Biochemistry and Biophysics, Vol. 369, No. 1, 1999, pp. 11-23. doi:10.1006/abbi.1999.1351

[17] A. Kawase, A. Fujii, M. Negoro, R. Akai, M. Ishikubo, H. Komura and M. Iwaki, "Differences in Cytochrome P450 and Nuclear Receptor mRNA Levels in Liver and Small Intestine between SD and DA Rats," Drug Metabolism and Pharmacokinetics, Vol. 23, No. 3, 2008, pp. 196-206. doi:10.2133/dmpk.23.196

[18] H. Sanada, M. Sekimoto, A. Kamoshita and M. Degawa, "Changes in Expression of Hepatic Cytochrome P450 Subfamily Enzymes during Development of AdjuvantInduced Arthritis in Rats," Journal of Toxicological Sciences, Vol. 36, No. 2, 2011, pp. 181-190. doi: $10.2131 /$ jts. 36.181

[19] E. Assenat, S. Gerbal-Chaloin, D. Larrey, J. Saric, J. M. Fabre, P. Maurel, M. J. Vilarem and J. M. Pascussi, "Interleukin $1 \beta$ Inhibits CAR-Induced Expression of Hepatic Genes Involved in Drug and Bilirubin Clearance," Hepatology, Vol. 40, No. 4, 2009, pp. 951-960.

[20] S. A. Kliewer, J. T. Moore, L. Wade, J. L. Staudinger, M. A. Watson, S. A. Jones, D. D. McKee, B. B. Oliver, T. M. Willson, R. H. Zetterstrom, T. Perlmann and J. M. Lehmann, "An Orphan Nuclear Receptor Activated by Pregnanes Defines a Novel Steroid Signaling Pathway," Cell, Vol. 92, No. 1, 1998, pp. 73-82.

\section{doi:10.1016/S0092-8674(00)80900-9}

[21] B. Goodwin, E. Hodgson and C. Liddle, "The Orphan Human Pregnane X Receptor Mediates the Transcriptional Activation of CYP3A4 by Rifampicin through a Distal Enhancer Module," Molecular Pharmacology, Vol. 56, No. 6, 1999, pp. 1329-1339.

[22] J. M. Maglich, C. M. Stoltz, B. Goodwin, D. HawkinsBrown, J. T. Moore and S. A. Kliewer, "Nuclear Pregnane $\mathrm{x}$ Receptor and Constitutive Androstane Receptor Regulate Overlapping but Distinct Sets of Genes Involved in Xenobiotic Detoxification," Molecular Pharmacology, Vol. 62, No. 3, 2002, pp. 638-646. doi: $10.1124 / \mathrm{mol} .62 .3 .638$

[23] T. Izukawa, M. Nakajima, R. Fujiwara, H. Yamanaka, T. Fukami, M. Takamiya, Y. Aoki, S. Ikushiro, T. Sakaki and T. Yokoi, "Quantitative Analysis of UDP-Glucuronosyltransferase (UGT) 1A and UGT2B Expression Levels in Human Livers," Drug Metabolism and Disposition, Vol. 37, No. 8, 2009, pp. 1759-1768. doi:10.1124/dmd.109.027227

[24] R. L. Yeager, S. A. Reisman, L. M. Aleksunes and C. D. Klaassen, "Introducing the TCDD-Inducible AhR-Nrf2 Gene Battery," Toxicological Sciences, Vol. 111, No. 2, 2009, pp. 238-246. doi:10.1093/toxsci/kfp115

[25] S. Chen, D. Beaton, N. Nguyen, K. Seneko-Effenberger, E. Brace-Sinnokrak, U. Argikar, R. P. Remmel, J. Trottier, O. Barbier, J. K. Ritter and R. H. Tukey, "Tissue-Specific, Inducible, and Hormonal Control of the Human UDPGlucuronosyltransferase-1 (UGT1) Locus," Journal of Biological Chemistry., Vol. 280, 2005, pp. 37547-37557. doi:10.1074/jbc.M506683200

[26] T. P. Dooley, R. Haldeman-Cahill, J. Joiner and T. W. Wilborn, "Expression Profiling of Human Sulfotransferase and Sulfatase Gene Superfamilies in Epithelial Tissues and Cultured Cells," Biochemical and Biophysical Research Communications, Vol. 277, No. 1, 2000, pp. 236-245. doi:10.1006/bbrc.2000.3643

[27] M. Runge-Morris, W. Wu and T. A. Kocarek, "Regulation of Rat Hepatic Hydroxysteroid Sulfotransferase (SULT2-40/41) Gene Expression by Glucocorticoids: Evidence for a Dual Mechanism of Transcriptional Control,' Molecular Pharmacology, Vol. 56, No. 6, 1999, pp. 11981206.

[28] J. Sonoda, W. Xie, J. M. Rosenfeld, J. L. Barwick, P. S. Guzelian and R. M. Evans, "Regulation of a Xenobiotic Sulfonation Cascade by Nuclear Pregnane X Receptor (PXR)," Proceedings of the National Academy of Sciences of the United States of America, Vol. 99, No. 21, 2002, pp. 13801-13806. doi:10.1073/pnas.212494599

[29] S. Uno, M. Uraki, A. Ito, Y. Shinozaki, A. Yamada, A. Kawase and M. Iwaki, "Changes in mRNA Expression of $\mathrm{ABC}$ and SLC Transporters in Liver and Intestines of the Adjuvant-Induced Arthritis Rat," Biopharmaceutics \& Drug Disposition, Vol. 30, No. 1, 2009, pp. 49-54. doi:10.1002/bdd.639 